\title{
Computational study of a radial flow turbine operates under various pulsating flow shapes and amplitudes
}

\author{
Ahmed Rezk ${ }^{1}$, Sidharth Sharma², Simon Barrans ${ }^{2}$, Abul Kalam Hossain ${ }^{1}$, Samuel P. Lee, Muhamad Imran ${ }^{1}$ \\ ${ }^{1}$ College of Engineering and Physical Science, Aston University, Birmingham, B4 7ET, UK \\ ${ }^{2}$ School of Computing and Engineering, University of Huddersfield, HD1 3DH, UK
}

\section{Abstract}

Radial flow turbines are extensively used in turbocharging technology due to their unique capability of handling a wide range of exhaust gas flow. The pulsating flow nature of the internal combustion engine exhaust gases causes unsteady operation of the turbine stage. This paper presents the impact of the pulsating flow of various characteristics on the performance of a radial flow turbine. A 3D computational fluid dynamic model was coupled with a 1D engine model to study the realistic pulsating flow. Applying square wave pulsating flow showed the highest degree of unsteadiness corresponding to $92.6 \%$ maximum mass flow accumulation due to the consecutive sudden changes of the mass flow rates over the entire pulse. Although saw-tooth showed a maximum mass flow accumulation value of $88.9 \%$, the mass flow rates entailed gradual change resulted in the least overall mass flow accumulation over the entire pulse. These two extremes constrained the anticipated performance of the radial flow turbine operates under realistic pulsating flow. Such constraints could develop an operating envelop to predict the performance and optimise radial flow turbines' power extraction under pulsating flow conditions.

Keywords: Turbine performance, Energy Conversion, CFD simulation, Efficiency curve 
Absolute Average Percent Deviation ( - )

$23 \quad \mathrm{C}_{\mathrm{p}}$ specific heat at constant pressure $\left(\mathrm{kJ} \mathrm{kg}^{-1} \mathrm{~K}^{-1}\right)$

$24 \quad \mathrm{C}_{\mathrm{s}}$

spouting velocity $\left(\mathrm{m} \mathrm{s}^{-1}\right)$

$25 \Delta \mathrm{t}$

time interval (s)

26 ER

total to static expansion ratio ( - )

$27 \mathrm{f}$

relative frequency

$28 \quad \mathrm{M}_{\mathrm{acc}}$

mass flow accumulation ( - )

$29 \dot{\mathrm{m}}$

mass flow rate $\left(\mathrm{kg} \mathrm{s}^{-1}\right)$

$30 \quad M F P$

mass flow parameter $\left(\mathrm{kg} \mathrm{k}^{-0.5} \mathrm{MPa}^{-1}\right)$

$31 \quad A P D$

Average Percentage Deviation ( - )

$32 N$

Rotation speed (rpm)

$33 \mathrm{~N}_{\text {data }}$

number of data points ( - )

$34 \quad \mathrm{~N}_{\text {interval }}$

number of intervals ( - )

$35 \mathrm{P}_{\mathrm{o}}$

Total pressure $(\mathrm{kPa})$

$36 t$

Time (s)

$37 \mathrm{~T}_{\mathrm{o}}$

total temperature $(\mathrm{K})$

$38 \mathrm{~T}_{\mathrm{s}}$

static temperature (K)

$39 U$

Tip speed $\left(\mathrm{m} \mathrm{s}^{-1}\right)$

$40 \quad W$

Work (Watt)

41 Greek

$42 \eta$

efficiency ( - )

$43 \omega$

rotational speed $\left(\mathrm{rad} \mathrm{s}^{-1}\right)$

$44 \tau$

torque (N.m)

$45 \gamma$

isentropic gas index ( - )

\section{Subscripts}

$47 \quad a$

actual

48 in

inlet

49 inst

instantons

50 is

isentropic

$51 \max$

maximum

$52 \quad \min$

minimum

53 out

outlet 


\section{Introduction}

55 Turbocharging technology is the most feasible to recover the waste energy in internal combustion engines (ICE) and its role in engine downsizing is indispensable $[1,2]$. In turbocharger, radial flow turbines are widely employed due to their unique capability to handle a wide range of operating conditions, high-power density, and reliable mechanical operation [3]. The turbocharger turbines' primary challenge is the high level of unsteadiness of the exhaust gasses flow, which is developed by the interaction between individual pulses produced by a finite number of cylinders and their propagation through the exhaust manifold $[4,5]$. Such a high level of unsteadiness lead to unpredictable off-design operation.

The experimental investigation of the pulsating flow effect on the turbine stage performance is virtually challenging due to the high operating temperature of the exhaust gases [6]. Accordingly, numerous studies have been conducted to numerically investigate the effect of the exhaust gasses pulsating flow on the turbine stage performance in turbocharging application. The thrust was to explore the change in the performance concomitant to the pulsating flow in the turbines compared to the steady flow operation. Conventional approaches, such as mean-line modelling and quasi-steady flow assumptions, could not capture these changes due to the complexity of pulsating flow admission [7-9].

Costall et al. [10] developed a 1-dimensional (1D) numerical code that imitated the turbocharger turbine stage integrated with the exhaust gasses system of an ICE to investigate the composition of a pulsating flow event from different harmonics using Fourier analysis. The study quantified the effect of different composed pulses on the instantaneous swallowing capacity of the turbine stage. Chiong et al. [11] employed a similar approach to correlate the impact of a volute size on the flow pressure and the mass flow rate at the inlet of a twin-entry turbine under pulsating flow admission, but it was not possible to predict the turbine stage efficiency. De Bellis et al. [12] developed a 1D model using GT-Power platform to investigate the performance of a twin-entry radial flow turbine under pulsating flow conditions. Although the fluid flow domain in this approach underwent a series of simplification and did not replicate a realistic pulse shape, the model showed a sufficient capability of predicting a turbine stage performance under the pulsating flow conditions.

The 1D modelling of turbomachines is not computationally intensive but it cannot envisage the flow behaviour inside the turbine stage. Marelli et al. [13] experimentally imitated the turbine flow unsteadiness by generating pulses of the hot air using a rotating valves mechanism whereby the influence of the pulsating flow on the performance of different turbine designs was experimentally assessed in comparison to the steady flow conditions. The same test facility was simulated using 1D fluid dynamic code by Piscaglia et al. [14] to predict the performance of the turbocharger turbines at different pulsating flow conditions. Padzillah and Chen [15, 16] experimentally imitated the exhaust gasses unsteadiness by generating pulses of cold air using a chopper plate mechanism. The experimentally generated pulses were used as boundary conditions for 1D and 3D 
computational fluid dynamics (CFD) analysis. The generated pulsating flow was employed by Ding et al. [17] to develop a 1D turbine model that built primarily on multiple meanline rotor models to predict the performance of radial and mixed flow turbines under unsteady flow conditions. Though the developed pulsating flow did not replicate the realistic pulses, the 3D CFD analysis generally developed better fundamental understanding of the pulsating flow in turbocharger turbine stage compared to 1D turbine model [15]. Galindo et al. [18] carried out a numerical study on a vanned turbocharger turbine by employing a 3D CFD approach, owing to its unique capability to conceive the flow behaviour. The study investigated the response to predefine the sinusoidal pulses of the various frequencies and amplitudes in different components of a vanned turbocharger turbine. The results showed that the most significant hysteresis and phase shift where quantified in the volute compared to other components due to its large characteristic length. Padzillah et al. [19] carried out a numerical study on a single entry vanned mixed flow turbine by employing a 3D CFD approach. The study envisaged the flow angle behaviour at the pulsating flow of different frequencies compared to steady flow conditions. The results showed a significant deviation between the hysteresis loop at the rotor inlet during pulsating flow compared to that at steady flow conditions, although the collapse of the hysteresis loop into a single line during the propagation from the volute inlet to the rotor inlet. The former study strongly agreed with that done by Hamel et al. [20], where a substantial deviation between the mixed flow turbine performance under pulsating flow at different frequencies and that at steady flow conditions was reported. Recently Galindo et al. [21] employed 3D CFD modelling capability to analyse the flow behaviours of twin-entry turbines as well as improving the predictability of $1 \mathrm{D}$ twin-entry turbine model.

The $1 \mathrm{D}$ engine models can imitate the realistic pulsating flow and provide more detailed pulse events. On reflection, R. Vijayakumar et al. [22] employed 1D engine modelling capability in order to design and manufacture a hot gas pulse generator to investigate the turbine performance under various pulsating flow conditions. The coupling of 1D and 3D-CFD turbine models can provide a better understanding of pulsating flow behaviour in turbocharger turbines [23, 24]. The 1D engine models consider nearly all parameters affecting pulsating flow development, e.g., engine firing, manifold passages, exhaust gas recirculation (EGR) and the back pressure generated by the muffler. Roclawski et al. [23] employed 3D CFD modelling to study the influence of the degree of reaction on radial flow turbines of various wheel sizes worked under a pulsating event developed by a 1D spark ignition engine model. The engine model developed a nearly realistic pulsating flow and enabled investigating the instantaneous variation of inlet flow angles and the corresponding influence on the turbine performance, e.g., mass flow hysteresis, torque hysteresis and turbine stage efficiency. The same modelling approach enabled Roclawski et al. [24] to carry out a multi-objective optimisation study to maximise the efficiency of a mixed flow turbine operates under pulsating flow conditions in spark ignition engine, considering the rotor dynamic and the fluid dynamic aspects. 
120 Each turbocharger is manufactured to serve a family of engines, each of which develops its unique pulsating 121 flow shape [25]. Besides, turbine characteristic maps developed by the manufacturer consists of discrete points; 122 each one quantifies the turbine performance under a steady flow condition [26]. Utilising the steady flow maps 123 or considering a single pulse shape to design and match a turbocharger leads to inefficient performance during 124 the actual operation. Accordingly, Lee et al. [27] employed 3D CFD numerical model to investigate the performance of a turbine stage that worked under a pulsating flow event acquired from a 1D Model of a Diesel engine as well as a group of predefined pulse shapes of fixed amplitude: square, sinusoidal and square.

The literature review reveals a clear gap of pulse shape impact on the turbine performance to achieve the optimal design and matching of the turbocharger. To the best of the authors' knowledge, the impact of different pulse shapes simultaneously with their amplitudes on the average cycle efficiency have not received any attention in the open literature and not reported yet. The present study aims to understand the impact of unsteady flow conditions of various pulse shapes and amplitudes on a radial turbine's performance. The objectives of the study are to (i) employ a 3D CFD modelling approach to imitate the turbine stage, owing to its favourable modelling capability; (ii) investigate the instantaneous and average cycle performance of a radial flow turbine under pulsating flow conditions; and (iii) investigate the potential use of average cycle efficiency envelop for better engine-turbocharger matching. The methodology of developing an envelop to predict the average cycle efficiency for radial flow turbines operate under pulsating flow condition is a critical contribution of this study. It is noteworthy mentioning that the effect of acoustic interactions at the inlet and outlet of the turbocharger is not included in this study.

\section{Turbine modelling}

\subsection{Numerical approach}

141 The turbine used in this study was part of a commercially available turbocharger for light-duty commercial road 142 vehicles. Figure 1 shows the final meshing and the computational domains of the simulated turbine. The turbine 143 dimensions are furnished in table 1. In this investigation, two-equation $\mathrm{k}-\omega \mathrm{SST}$ turbulence model was used. In 144 comparison to other turbulence models techniques, k- $\omega$ Shear Stress Transport (SST) showed a high level of accuracy and versatility [23, 28]. Multiple Reference Frame (MRF) approach was employed to model the interface between the turbine wheel and volute. MRF showed a proven validity in turbomachinery modelling under pulsating flow conditions, albeit its low computational cost [24, 29].

For pulsating flow analysis, the turbine rotational speed was kept constant at $161922 \mathrm{rpm}$. At the given speed, the intermediate point on the steady flow map of 2.2 pressure ratio was chosen, which showed a reasonable deviation from the experimental results as illustrated in figure 5. The change of the turbine speed due to pulsating flow is negligible, and the assumption of using constant turbine speed for pulsating flow analysis was 
152 widely practised in unsteady flow numerical analysis $[15,24]$. In this study, the numerical computations were 153 executed using ANSYS-CFX V17.1 platform. A timestep of $10^{-4}$ s, i.e. $97^{\circ}$ of rotor rotation per iteration, is 154 employed. It is worth emphasising that the fluctuations introduced by the pulse are of much higher amplitude 155 and timescale than the turbine blade passing. Therefore, the choice for timestep size is based on the intent to 156 capture the pulse physics is a computationally efficient manner. Furthermore, the simulations are solved for 1570.06 s (i.e. approximately 160 rotation of the impeller, of which $0.04 \mathrm{~s}$ are regarded as initial transients. The 158 adequate convergence of numerical results was achieved by obtaining the root mean squared residuals under $15910^{-4}$

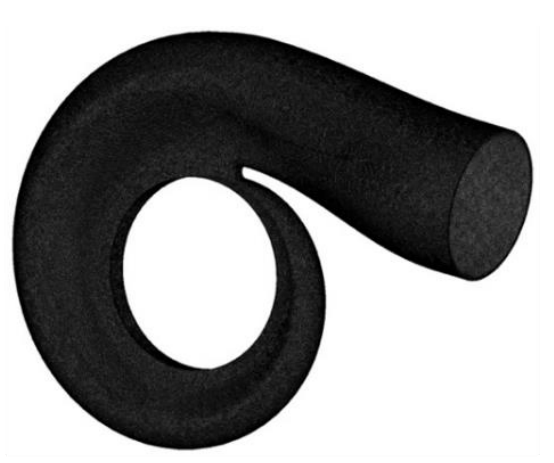

(a)

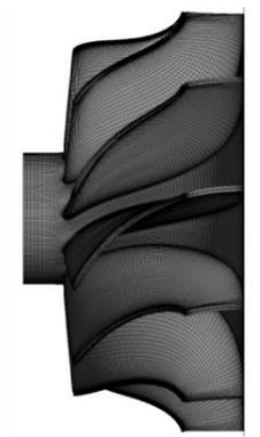

(b)

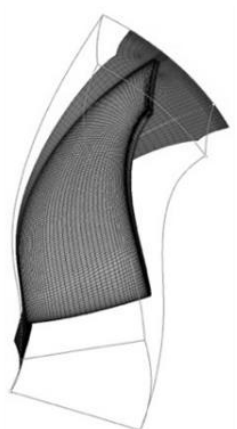

(c)

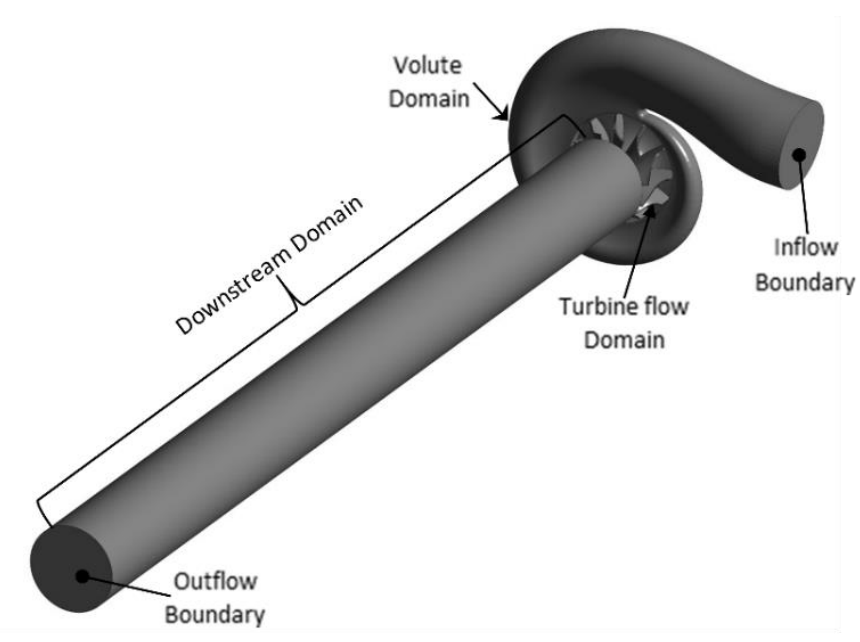

(d)

160

Figure 1 - The simulated geometry (a) Turbine grid: (a) volute grid, (b) rotor grid and (c) mid-span mesh and (d) computational domains.

Table 1 - The geometrical data of the simulated turbine

\begin{tabular}{|l|l|l|l|}
\hline Parameter & Dimension & Parameter & Dimension \\
\hline Turbine inducer diameter & $38 \mathrm{~mm}$ & Number of blades & 11 \\
\hline Turbine exducer diameter & $32 \mathrm{~mm}$ & Turbine inlet flow area & $6.45 \times 10^{-6} \mathrm{~m}^{2}$ \\
\hline Hub diameter & $12 \mathrm{~mm}$ & Volute inlet flow area & $2.90 \times 10^{-6} \mathrm{~m}^{2}$ \\
\hline
\end{tabular}




\subsection{Boundary conditions}

165 Mass flow inlet boundary was chosen at the volute inlet to allow distinct pulsating flow shapes acting on the 166 turbine wheel in case of transient operation; a similar approach was also found in the literature [25, 30, 31]. 167 The chosen boundary might numerically influence the acoustic effect in the simulation model but investigating 168 the acoustic reflections associated with the inlet flow boundary is out of the scope of this study. A spatially 169 uniform temperature of $923 \mathrm{~K}$ was defined at the volute inlet. The fluid media was ideal gas of an average 170 specific heat $C p=1151 \mathrm{~J} / \mathrm{kg} \mathrm{K}$ corresponding to Diesel exhaust gases at the predefined inlet temperature. 171 Average static pressure outflow boundary was chosen at atmospheric pressure and downstream domain was 172 placed in order to avoid the interference between the outflow boundary, and the pressure fluctuation at the 173 turbine outlet [18]. Practically, the exhaust gas flow downstream of the turbine was dictated by space 174 constraints around the engine, but the effect of downstream domain configurations was outside the scope of 175 this study.

\subsection{Computational grid}

177 The grid of any computational model should accurately reproduce the geometry to yield credible numerical 178 predictions. The key decisions involved in the spatial discretisation of the turbine stage model include 179 determining the type and number of the cells for the mesh for optimal computational accuracy. Following the 180 recommended grid structure by Galindo [28], an unstructured tetrahedral mesh was developed for the volute 181 and outlet domains using ICEM CFD. A structured mesh was defined for the rotor region using ANSYS TurboGrid. For a reasonable resolution of viscous sublayer, the boundary layer flow modelled using the numerical grid with the value of $y^{+} \leq 3$.

184 The computational domain was assessed to yield credible results by achieving flow solutions independent of 185 the mesh. The steady-state operation of the turbine is modelled with a continuous increase in mesh density until the variation in the flow solution of two consecutive cases reaches a sufficiently small value that is computationally inefficient. Grid densities ranging from 8 million cells to above 20 million cells were explored to establish flow independence from the spatial domain. The computed values of the normalised stage efficiency and normalised mass flow for the various numerical domains are presented in Figure 2. The grid of approximately 16 million cells was selected as the computationally optimal configuration. 


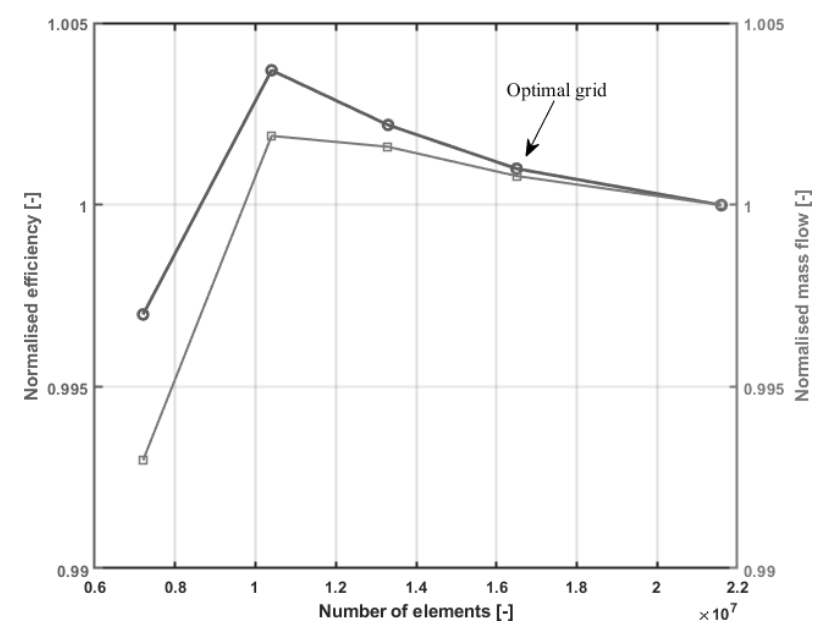

Figure 2 - Efficiency and mass flow values for various grids normalised by the value computed for the finest grid.

\subsection{Pulsating flow modelling}

194 The engine pulsating flow was obtained from a 1D engine model available in GT-Power liberary for a 2L, 4 195 cylinders turbocharged diesel engine. Figure 3 shows a pulsating flow of the exhaust gases at the inflow 196 boundary during an entire steady engine cycle at $1500 \mathrm{rpm}(0.08 \mathrm{~s})$ and $100 \%$ load. The chosen engine speed 197 represents the average of the common operating range within the duty cycle of light-duty road vehicles [32].

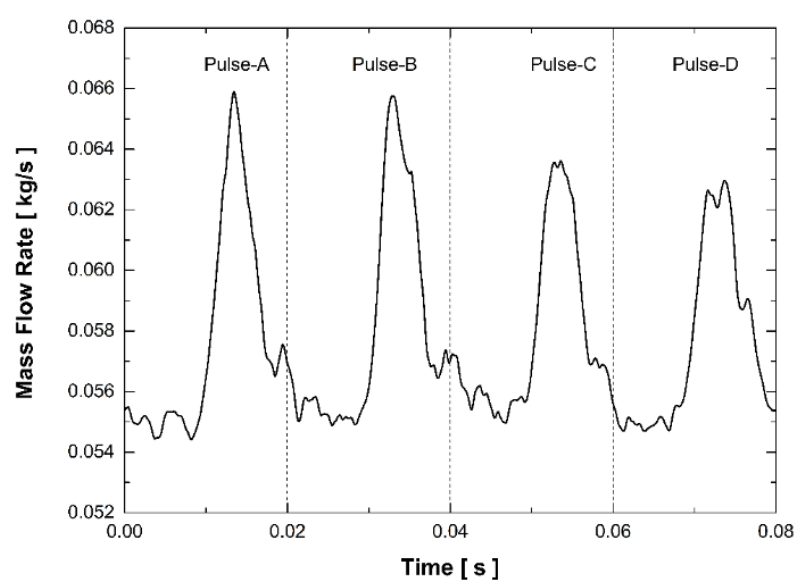

200 In this study, two pulse events were chosen (A and C), each showing distinct differences in shapes and amplitudes. A number of predefined pulse shapes were developed: square, sinusoidal, triangle, ramping-up saw-tooth, and ramping-down saw-tooth. The engine and predefined pulse shapes were scaled up at a constant frequency of $50 \mathrm{~Hz}$. The pulsating flow amplitudes were identified using the inlet-mass-flow pulsation number as a redefinition to the pressure pulsation number used by Roclawski [19] as shown in equation 1. 
206 The parameters $\dot{m}_{i n, \max }$ is the maximum mass flow in the pulse, $\dot{m}_{i n, \text { min }}$ is the minimum mass flow and $\dot{m}_{\text {mean }}$ 207 is the mean mass flow.

\section{3. Results and Discussion}

\subsection{Turbine modelling validation}

210 The simulated turbine was tested and mapped at the manufacturer platform using a steady flow gas stand as 211 per SAE standard, whereby the developed computational approach was validated [33, 34]. Figure 4 is a 212 schematic of the experimental gas stand according to the SAE standard. Two parameters were determined using 213 experimentally measured fluid flow properties: stage efficiency $\left(\eta_{\text {stage }}\right)$ and mass flow parameter $(M F P)$, as 214 shown in equations 2 and 3.

$215 \quad \eta_{\text {stage }}=\frac{\left(T_{o_{\text {in }}}-T_{S_{\text {out }}}\right)}{\left(T_{o_{\text {in }}}-T_{S_{\text {out }, \text { is }}}\right)}$

$216 \quad M F P=\frac{\dot{m} \sqrt{T_{O_{\text {in }}}}}{P_{O_{\text {in }}}}$

217 The $\dot{m}, T_{O_{\text {in }}}$ and $P_{O_{\text {in }}}$ are the stage inlet conditions of mass flow rate, total temperature and total pressure, 218 respectively. $T_{S_{\text {out }}}$ and $T_{S_{\text {out is }}}$ are the static temperature and isentropic temperatures at the stage outlet. 219 Practically, the kinetic energy at the stage outlet is wasted and does not contribute to the energy produced by 220 the turbine stage. Therefore, it was excluded in the stage efficiency.

221 Figure 2 compares the predicted stage efficiency and mass flow parameter and their actual analogous values 222 that were supplied by the manufacturer based on the same operating conditions. The average percentage 223 deviation (APD) and absolute average percentage deviation (ABS-PD) between the predicted and tested stage 224 efficiency values are 2.64 and 2.64, and mass flow parameter are -3.54 and 3.54, according to Figure 2. Although 225 the CFD model over-predicts the turbine stage efficiency, it generally indicates a good agreement with the 226 experimental results and the open literature [35]. The CFD model over-predicts the turbine efficiency primarily 227 because of the adiabatic assumption whilst thermal losses are inevitable in an experimental facility [36]. Smooth wall assumption is a secondary reason that led to the overprediction of the developed model. The validity of the simulation approach during the unsteady operation was previously investigated by Lee and Barrans [37]. 


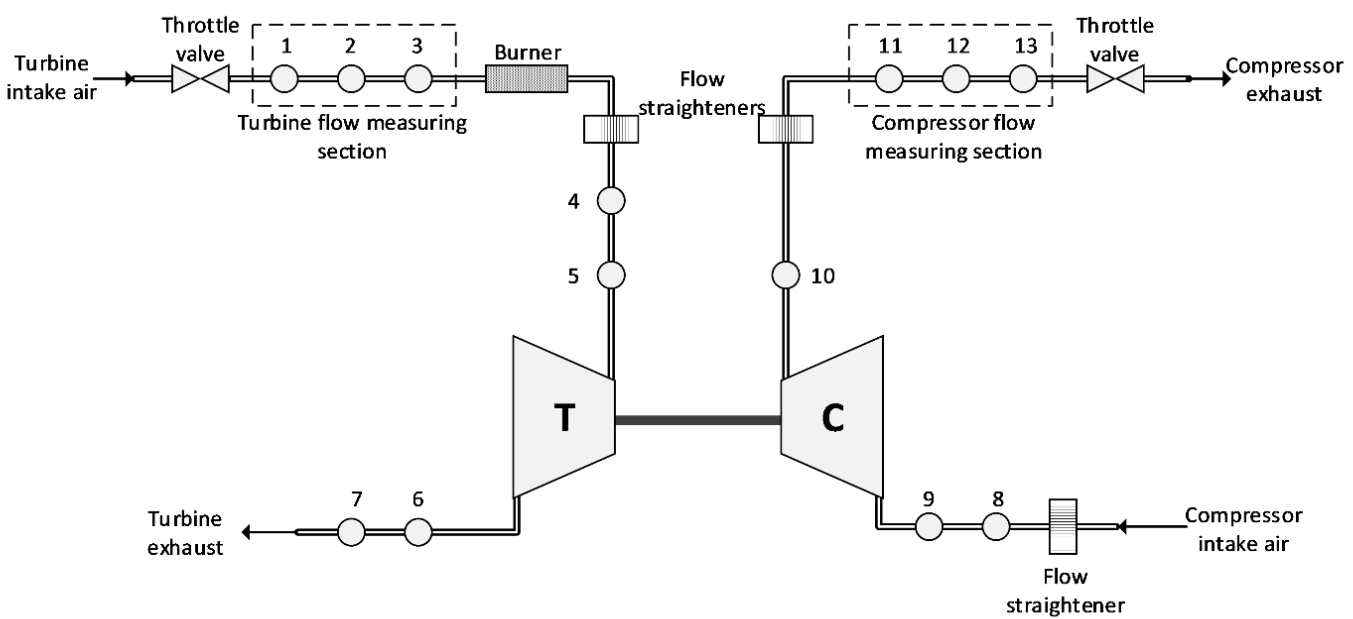
(1) Static pressure measurement
(2) Pressure differential
(4) turbine inlet total temperature
(5) Turbine inlet total pressure
(7) Turbine discharge total temperature
(8) Compressor inlet static pressure
(10) Compressor discharge pressure
(11) Static pressure measurement
(13) Total temperature
$\mathrm{T}$ - Turbine

3) Total temperature

(6) Turbine discharge total pressure

(9) Compressor inlet total temperature

(12) Pressure differential

C - Compressor

Figure 4 - Schematic of standard turbocharger gas stand [32]
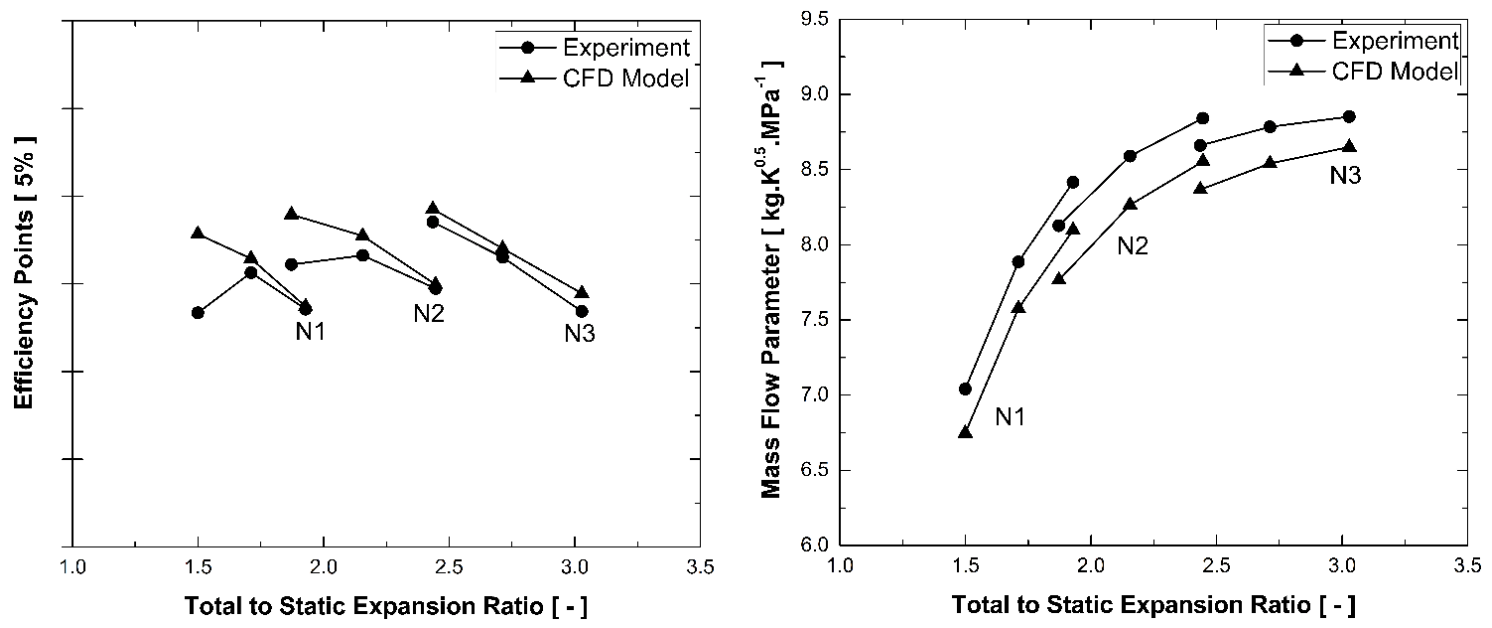

Figure 5 - CFD Model Validation. N1, N2 and N3 are turbine speed. N1=133102 rpm, N2=161922 rpm, N3=185889 rpm

\subsection{Mass flow accumulation}

235 The mass flow rate at the volute-outlet is the effective mass flow rate, and its phase and amplitude slightly vary

236 from that at the in-flow boundary. The mass flow accumulation $\left(M_{a c c}\right)$ is the parameter that quantifies the 237 instantaneous difference between the mass flow at in-flow boundary and the effective mass flow with respect 238 to the mean mass flow rate as shown in equation 4.

$M_{a c c}=\frac{\dot{m}_{\text {volute }_{\text {in }}}-\dot{m}_{\text {volute }_{\text {out }}}}{\dot{m}_{\text {mean }}} \%$ 
240 Where $\dot{m}_{\text {volute }_{\text {in }}}$ is the mass flow rate at the volute inlet, $\dot{m}_{\text {volute }}$ out is the mass flow rate at the volute outlet 241 or the effective flow, and $\dot{m}_{\text {mean }}$ is the mean mass flow rate or steady flow map mass flow rate.

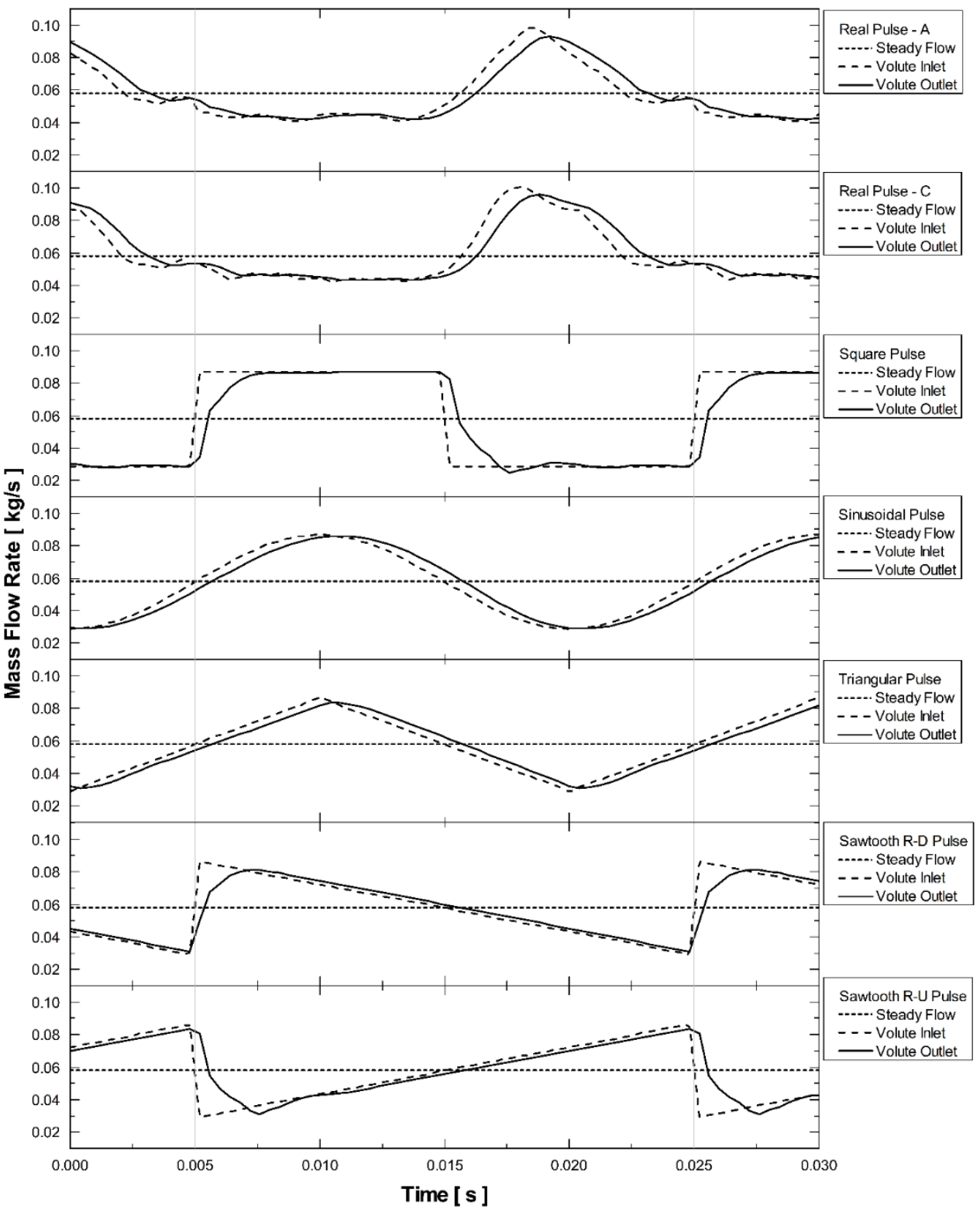

Figure 6 - Volute inlet pulsating mass flow, Pulsation Number $=1$.

244 Figure 6 presents the temporal pulse shapes at inflow boundary, volute-outlet/rotor-inlet, and the corresponding steady flow at the midpoint of the turbine map at a turbine speed of $161922 \mathrm{rpm}\left(\mathrm{N}_{2}\right)$. The corresponding mass flow accumulations for each pulse shape is shown in Figure 7 . The square pulse exhibits sudden changes in mass flow rate at two points corresponding to two spikes of mass flow accumulation during the entire cycle: filling and emptying. The identified maximum absolute mass flow accumulation was $92.6 \%$. The flow stabilised and exhibited zero mass flow accumulation after the sudden filling, whereas an oscillation of the 
mass flow accumulation was identified after the sudden emptying. Unlike the volute emptying, the mass flow rate plateau was long enough to stabilise the flow through the volute during filling.

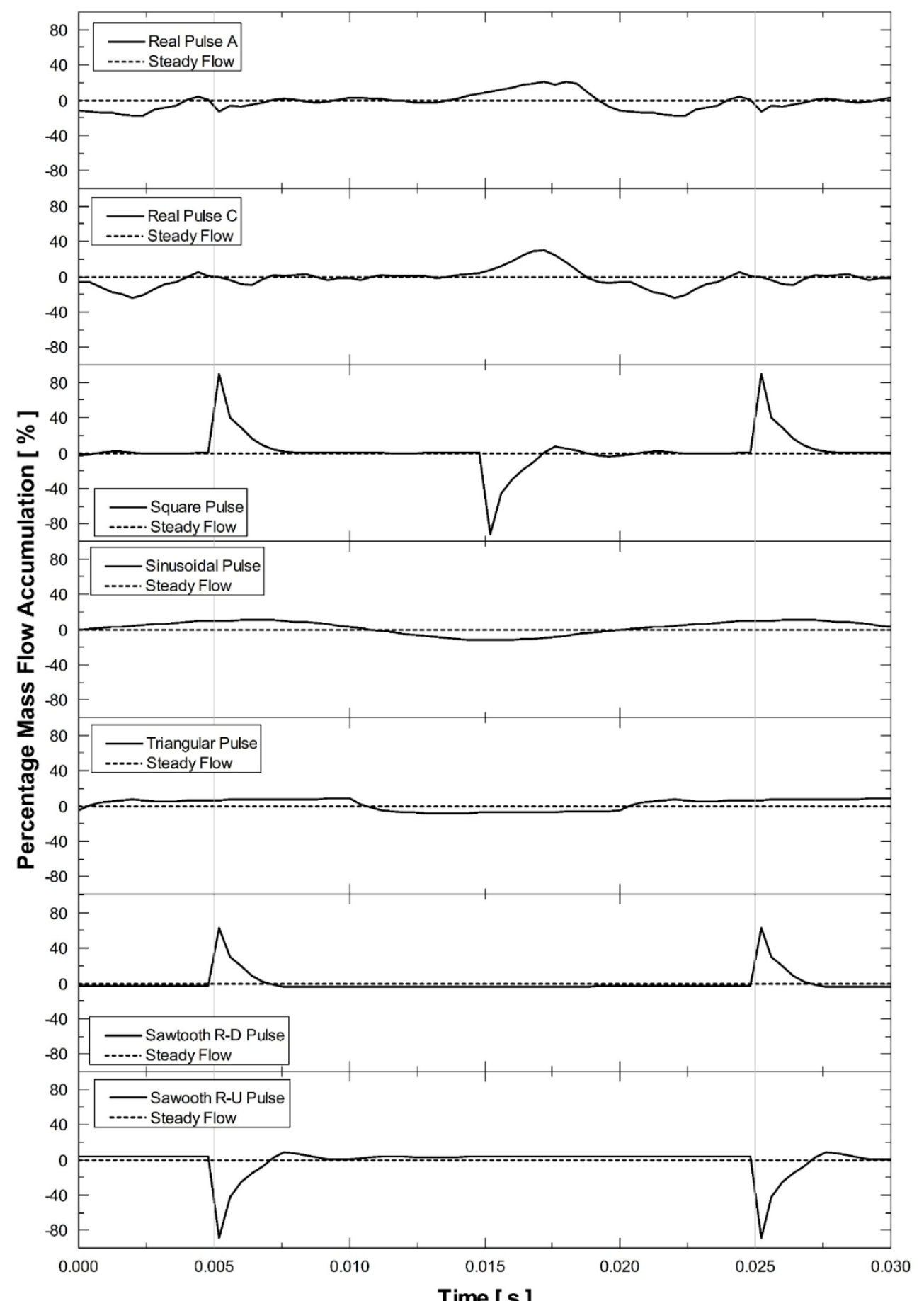

Time [s]

Figure 7 - Volute mass flow accumulation determined using different inlet pulse shapes

254 Saw-tooth waves showed a sudden change in the mass flow rate once each cycle corresponding to a single spike 255 of mass flow accumulation; sudden emptying during ramping-up or sudden filling during ramping-down saw256 tooth pulses. The sudden changes in the mass flow rate generate instantaneous lags between in-flow boundary 257 and effective mass flow rates. During sudden emptying, such a lag is followed by an oscillation around the in- 
flow, which stabilised afterwards to give a small positive accumulation. The oscillation was caused by the inertia of the initially high mass flow rate exit from the volute, causing the volute to over-empty when the inlet mass flow was suddenly dropped. The absolute maximum flow accumulation identified was $88.9 \%$ for a ramping-up saw-tooth pulse.

In ramping down saw-tooth, the oscillation after the sudden filling was not observed and a constant amount of negative mass flow accumulation identified; rather, the volute damped the sudden change in mass flow. The absolute maximum mass flow accumulation was $62.6 \%$ for a ramping-down saw-tooth pulse. The flow inertia reduced the peak values of mass flow between volute inlet and outlet of saw-tooth pulse shapes. Other pulse shapes showed smaller mass flow accumulation levels due to the gradual changes in inlet mass flow. It results in less significant mass flow accumulation by sinusoidal and triangular waves compared to the realistic engine pulse shapes.

\subsection{Cycle average efficiency}

270 As shown in equation 5, the cycle average rotor efficiency $\left(\eta_{\text {Cycle Average }}\right)$ is defined as the ratio between the 271 total actual output work done by the turbine rotor and the total isentropic work available by the exhaust gases 272 over the entire wave [38]. The instantaneous rotor efficiency $\left(\eta_{\text {Inst }}\right)$ is defined as the ratio between the actual 273 output work and the isentropic work at a specific time, shown in equation 6.

$\eta_{\text {Cycle Average }}=\frac{\int_{0}^{t-c y c l e} \tau \cdot \omega d t}{\int_{0}^{t-c y c l e} \dot{m}_{\text {volute }_{\text {out }}} \cdot C_{p} \cdot T_{0} \cdot\left(1-E R^{\frac{1-\gamma}{\gamma}}\right) d t}$

$\eta_{\text {Inst }}=\frac{[\text { Actual Work }]_{t}}{[\text { Isentropic Work }]_{t}}=\frac{[\tau \cdot \omega]_{t}}{\left[\dot{m}_{\left.\text {volute }_{\text {out }} \cdot C_{p} \cdot T_{o} \cdot\left(1-E R^{\frac{1-\gamma}{\gamma}}\right)\right]_{t}}\right.}$

276 Where $\tau$ is the torque delivered to the turbocharger shaft by the gas flow over the turbine blades, and $\omega$ is the turbine speed. $\gamma$ and $C_{p}$ are the isentropic index and specific heat of the exhaust gasses. The isentropic work was determined based on the effective mass flow rate and total to static expansion ratio $(E R)$ across the turbine wheel. In this study, 50 data points were used to determine the average cycle efficiency of the turbine over the entire pulse event of $0.02 \mathrm{~s}$. At each time step, the mass average physical quantities were determined across the rotor inlet and exit flow areas.

282 Figure 8 shows the normalised average cycle efficiency of the turbine wheel working under different pulse 283 shapes and amplitudes compared to the steady flow operation. Pulsation number of zero corresponds to steady 284 flow operation of $100 \%$ normalised average cycle efficiency. 


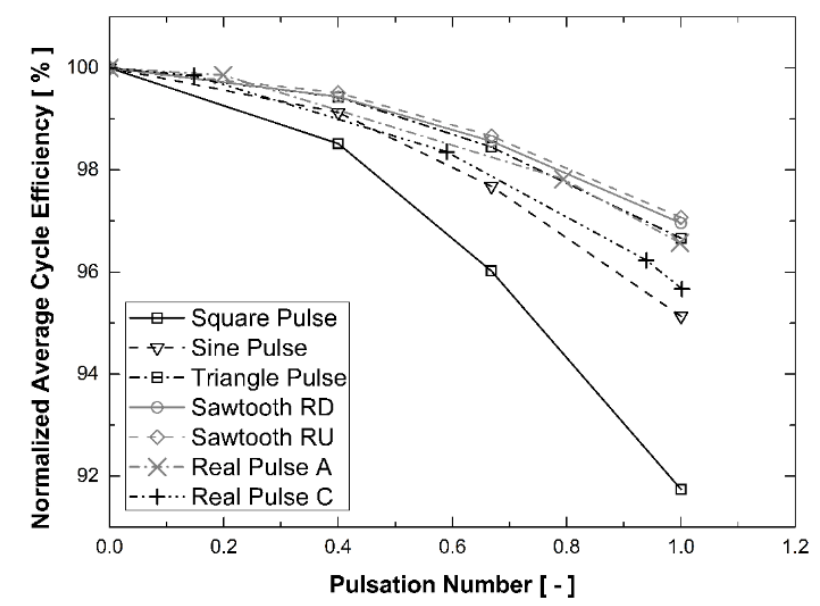

Figure 8 - Average Cycle efficiency of different pulse shapes and amplitudes

287 Although the inlet pulsating flow potentially holds more isentropic power than a steady flow, the results showed that the average cycle efficiency of the turbine rotor running at the same speed under pulsating flow conditions was lower than that for steady flow conditions $[34,39]$.

The square wave showed the lowest rotor efficiency at all pulse amplitudes, followed by the sinusoidal wave. Ramping-up and ramping-down saw-tooth pulses showed the highest values of the average cycle efficiency. The average cycle efficiency curve of the triangle pulse is between that of sinusoidal pulse and ramping-down saw-tooth pulse.

Engine pulse A had equal ramp-up and ramp-down periods of approximately $0.005 \mathrm{~s}$; this resulted in moderate mass flow accumulation shown in figure 7 . In contrast, engine pulse $\mathrm{C}$ had a relatively shorter ramp-up period and held the higher mass flow rate for a shorter period; this resulted in increased peak accumulation and a reduced cycle efficiency similar to the sine wave pulse.

\subsection{Instantaneous turbine performance.}

The instantaneous turbine performance under pulsating flow conditions provides useful insight into the differences in cycle average efficiency trends. The instantaneous performance of the turbine wheel was assessed using the ratio of turbine wheel tip speed to spouting velocity ratio $\left(U / C_{S}\right)$ and the corresponding instantaneous efficiency. The spouting velocity $\left(C_{S}\right)$ is the flow velocity equivalent to isentropic efficiency drop in the turbine and can be determined using equation 7.

$C_{S}=\sqrt{2 \cdot C_{p} \cdot T_{o_{\text {in }}} \cdot\left(1-E R^{\frac{1-\gamma}{\gamma}}\right)}$

Figures 9 and 10 show change in the instantaneous turbine efficiency and the corresponding change in $U / C_{s}$ in the time domain, respectively. It was observed that the performance of the radial flow turbine was highest for $U / C_{S}$ ratio of between 0.70 and 0.75 , which corresponds to the range of optimal incidence angles for the 
turbine stage of between $-10^{\circ}$ and $-20^{\circ}$. In this study, the turbine performance does not peak at the corresponding steady flow operation since its steady-state spouting velocity ratio at $161922 \mathrm{rpm}$ is $U / C_{s}=0.55$.

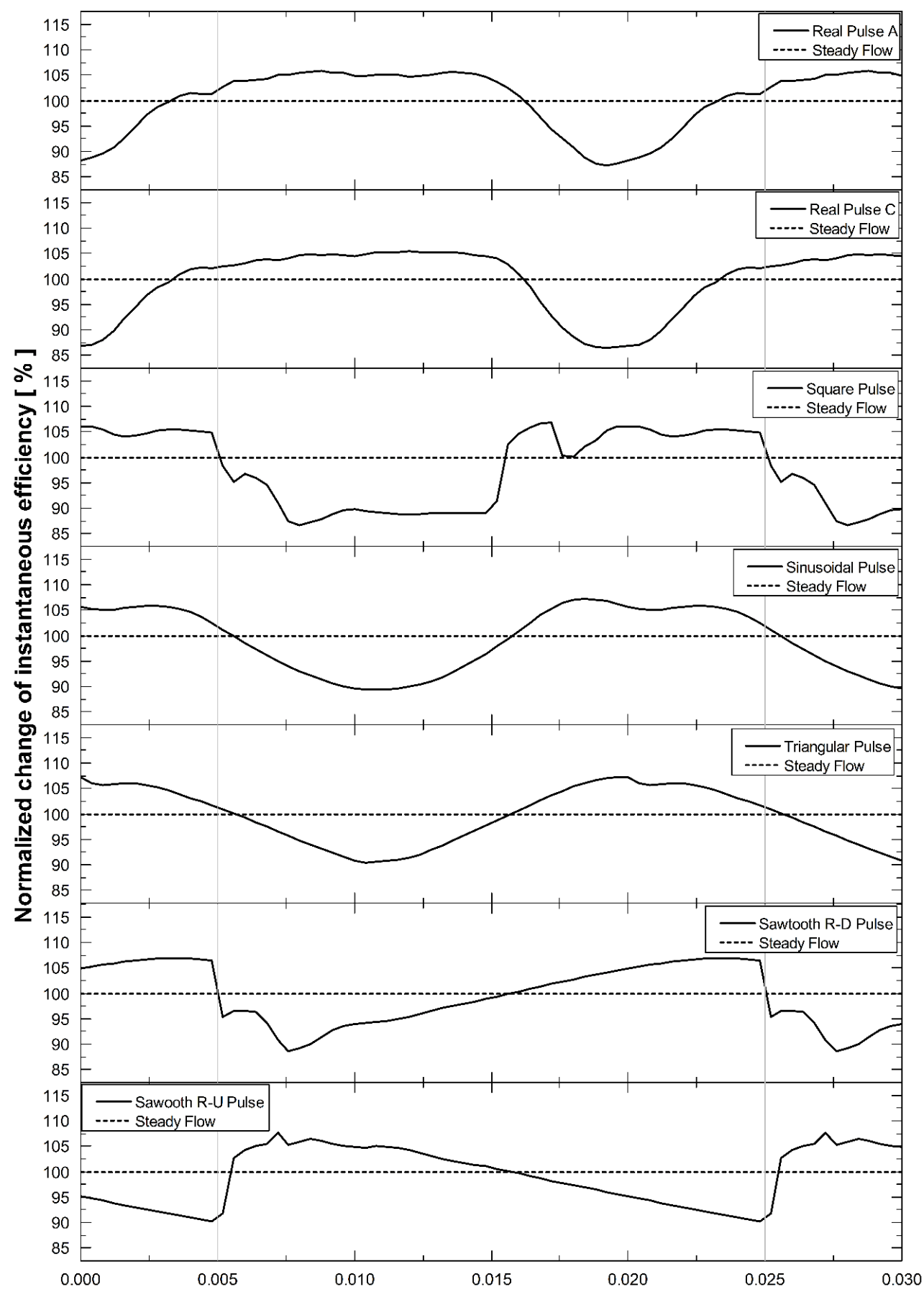

Time [s]

Figure 9 - The instantaneous efficiency in time domain

313 To break down data shown in figures 9 and 10, the data points were sub-grouped according to the interval of $314 U / C_{s}$ in which they lay, and intervals of 0.05 were used. For each subgroup, total actual work $\left(W_{a, \text { interval }}\right)$, total 315 isentropic work $\left(W_{s, \text { interval }}\right)$ done as a proportion of their cycle total, and the corresponding average rotor 
efficiency were determined using equations 8-10. The relative frequency is a statistical term that determines the number of times that an event occurs. In this investigation, the relative frequency $f$ term was used to identify the time spent within each velocity ratio interval as a fraction of the total cycle time (equation 11).

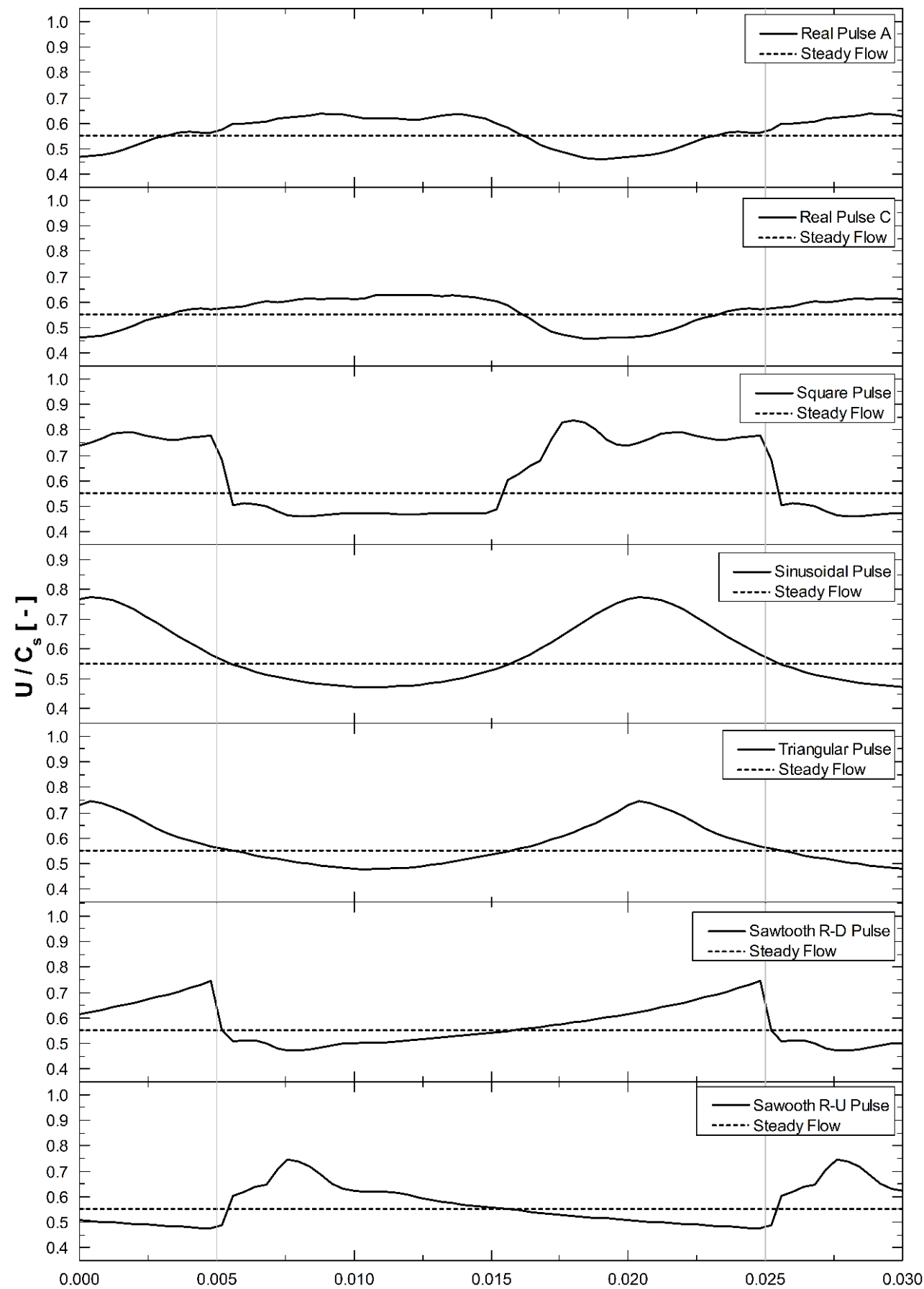

Time $[\mathbf{s}]$

$321 \quad W_{a, \text { interval }}=\frac{\int_{0}^{t-\text { interval }} \tau . \omega d t}{\int_{0}^{t-c y c l e} \tau . \omega d t}$ 
$W_{\text {is,interval }}=\frac{\int_{0}^{t-\text { interval }} \dot{m}_{\text {volute }_{\text {out }}} \cdot C_{p} \cdot T_{o} \cdot\left(1-E R^{\frac{1-\gamma}{\gamma}}\right) d t}{\int_{0}^{t-c y c l e} \dot{m}_{\text {volute }_{\text {out }}} \cdot C_{p} \cdot T_{o} \cdot\left(1-E R^{\frac{1-\gamma}{\gamma}}\right) d t}$

$\eta_{\text {interval }}=\frac{\int_{0}^{t-\text { interval }} \tau \cdot \omega d t}{\int_{0}^{t-\text { interval }} \dot{m}_{\text {volute }_{\text {out }}} \cdot C_{p} \cdot T_{0} \cdot\left(1-E R^{\frac{1-\gamma}{\gamma}}\right) d t}$

$324 f=\frac{N_{\text {interval }} \cdot \Delta t}{t_{\text {cycle }}}$

325 Where $N_{\text {interval }}$ is the number of data point at each interval, $\Delta t$ is the time step of each data point and $t_{c y c l e}$ is the cycle time of $0.02 \mathrm{~s}$. The time step for each data point was fixed at $4 \times 10^{-4} \mathrm{~s}$ as 50 data point were collected each cycle. As shown in figure 11 and for all pulse shapes, only a small proportion of the work done during the pulse event occurs at the velocity ratio giving the highest efficiency. The square and sinusoidal waves have a higher fraction of work done at the low-efficiency region of $0.45<U / C_{S}<0.50$ compared to the other pulses. Also, these waves contradict other waveforms, as delivered work at $0.75<U / C_{s}<0.80$ at a lower efficiency than peak efficiency. The square wave has also delivered work at $0.80<U / C_{S}<0.85$ compared with zero work delivered by any other pulse shape.

To explore the link between rotor efficiency during each interval $\left(\eta_{\text {interval }}\right)$ and the proportion of a pulse spent in each efficiency range $(f)$, the product of these two terms is shown in figure 10. Sinusoidal and saw-tooth pulses spent a relatively shorter time in the velocity ratio range of $0.55<U / C_{S}<0.75$ and hence delivered work in the most inefficient velocity ranges. Realistic engine pulses spent a relatively long time in the range of $0.60<U / C_{s}<0.65$. Using different pulsating flow characteristics corresponding to different engine operating point might lead to different distribution to the work extraction, but it is outside of the scope of this investigation.

\subsection{Pulsating flow operating envelop}

341 Building on the observed results, the average cycle efficiency region between the saw-tooth and sinusoidal 342 pulses, as shown in figure 8, could be potentially used as an envelope to predict the turbine performance under pulsating flow conditions. Despite the fact that the turbocharger turbine might operate under significantly different conditions, the borders of the operating envelop will not change significantly. On the one hand, actual pulsating flow will unlikely show any sudden change of the mass flow rate; therefore, the lower border of the operating envelop will tend more towards sinusoidal wave and rarely towards square wave. On the other hand, actual pulsating flow is not anticipated to provide a slow change in the mass flow rate between the two peaks such as saw-tooth pulses; thus, the upper border of the operating envelop will be hardly exceeded. However, exceeding the upper border will have a positive impact on the turbine performance. 
350 The envelop can be practically used as targets for the production of exhaust gas pulses with more efficient forms and better matching between the turbocharger and an engine. To achieve more efficient exhaust pulses, engine timing and the exhaust manifold layout could be manipulated. Practically, it is unlikely to redesign the engine timing for a sole reason as it is primarily used to achieve efficient and clean combustion. The exhaust manifold manipulation could lead to better pulsating flow composition for more efficient energy extraction, perhaps targeting ramping down saw-tooth pulse shape.

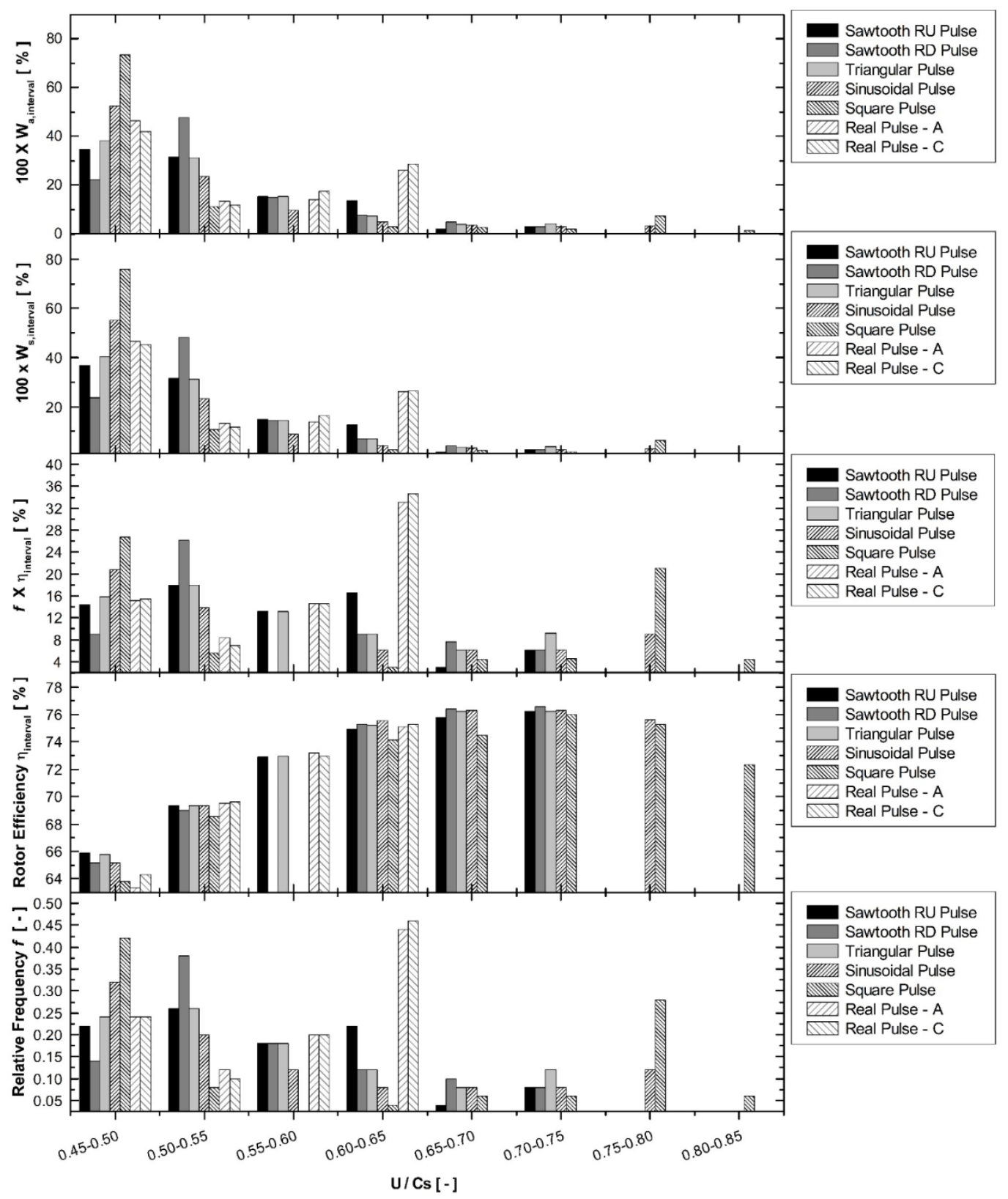

Figure 11 - Pulsating flow operating points - subgroups analysis 


\section{Conclusion}

359 This work investigated the performance of radial flow turbine working under unsteady mass flow condition in 360 the turbocharging application. A 3D computational fluid dynamic model for a radial turbine stage was developed and validated against experimental results provided by the manufacturer.

Different pulsating flow shapes and amplitudes were applied at the inflow boundary: square, sinusoidal, triangular, ramping-up saw-tooth, ramping-down saw tooth and realistic pulse shapes developed by a 1D GTPower engine model. The pulsating flow frequency was $50 \mathrm{~Hz}$ corresponding to $1500 \mathrm{rpm}$ of 2L, 4-cylinder engine at full-load operation.

The results showed a high degree of flow unsteadiness and mass flow accumulation of $92.6 \%, 88.9 \%$ and $62.6 \%$ by applying square pulse, ramping-up saw-tooth and ramping-down saw-tooth due to the sudden filling and emptying of the volute; unlike other pulsating flow shapes that exhibited lower levels of mass flow accumulation due to the gradual changes in inlet mass flow.

Investigating the average cycle performance of the turbine stage during the pulse events showed that the average cycle efficiency values of the turbine stage working under engine realistic pulsating flow lies between the average cycle lines of the turbine stage working under sinusoidal and saw-tooth pulse shapes. So that, the area between average cycle efficiency lines for sinusoidal and saw-tooth pulse shapes could be potentially used as an operating envelop to predict the performance of the turbine stage working under actual pulsating flow conditions, which is the critical contribution of this study.

The trends of average cycle efficiency were further investigated by studying the change in the instantaneous performance of the turbine stage during the pulse event of different shapes. The square and sinusoidal pulse shapes showed the lowest values of average cycle efficiency resulting from the less efficient work delivered for longer periods during the pulse event.

Investigating the effect of acoustic interactions at the turbocharger inlet and outlet were not included in this study. Acoustic interactions might affect the predicted efficiencies of the 3D modelled turbocharger. Therefore, studying the acoustic interaction effect is recommended as a future study, as well as investigating more engine pulsating flow under different engine operating conditions and frequencies in comparison to the same range of predefined pulse shapes.

\section{Acknowledgement}

The authors wish to thank BorgWarner Turbo Systems for sponsoring this project and providing the required data to conduct this study. 


\section{References}

[1] Marelli, S., M. Capobianco, and G. Zamboni, Pulsating flow performance of a turbocharger compressor for automotive application. International Journal of Heat and Fluid Flow, 2014. 45: 158-165.

[2] Bontempo, R., M. Cardone, M. Manna, and G. Vorraro, Steady and unsteady experimental analysis of a turbocharger for automotive applications. Energy Conversion and Management, 2015. 99: 72-80.

[3] Zhu, S., K. Deng, and S. Liu, Modeling and extrapolating mass flow characteristics of a radial turbocharger turbine. Energy, 2015. 87: 628-637.

[4] Liu, Z. and C. Copeland, New method for mapping radial turbines exposed to pulsating flows. Energy, 2018. 162: 1205-1222.

[5] Serrano, J.R., R. Navarro, L.M. García-Cuevas, and L.B. Inhestern, Contribution to tip leakage loss modeling in radial turbines based on 3D flow analysis and 1D characterization. International Journal of Heat and Fluid Flow, 2019. 78: 108423.

[6] Yang, M., K. Deng, R. Martines-Botas, and W. Zhuge, An investigation on unsteadiness of a mixed-flow turbine under pulsating conditions. Energy Conversion and Management, 2016. 110: 51-58.

[7] Rajoo, S., A. Romagnoli, and R.F. Martinez-Botas, Unsteady performance analysis of a twin-entry variable geometry turbocharger turbine. Energy, 2012. 38: 176-189.

[8] Galindo, J., A. Tiseira, P. Fajardo, and L.M. García-Cuevas, Development and validation of a radial variable geometry turbine model for transient pulsating flow applications. Energy Conversion and Management, 2014. 85: 190-203.

[9] Romagnoli, A., R.F. Martinez-Botas, and S. Rajoo, Steady state performance evaluation of variable geometry twin-entry turbine. International Journal of Heat and Fluid Flow, 2011. 32: 477-489.

[10] Costall, A. and R.F. Martinez-Botas. Fundamental Characterization of Turbocharger Turbine Unsteady Flow Behavior. in ASME Turbo Expo, Power for Land, Sea and Air, GT2007-28317. 2007. Montreal, Canada.

[11] Chiong, M.S., S. Rajoo, R.F. Martinez-Botas, and A.W. Costall, Engine turbocharger performance prediction: One-dimensional modeling of a twin entry turbine. Energy Conversion and Management, 2012. 57: 68-78.

[12] De Bellis, V., S. Marelli, F. Bozza, and M. Capobianco, 1D Simulation and Experimental Analysis of a Turbocharger Turbine for Automotive Engines Under Steady and Unsteady Flow Conditions. Energy Procedia, 2014. 45: 909-918.

[13] Marelli, S. and M. Capobianco, Steady and pulsating flow efficiency of a waste-gated turbocharger radial flow turbine for automotive application. Energy, 2011. 36: 459-465.

[14] Piscaglia, F., A. Onorati, S. Marelli, and M. Capobianco, A detailed one-dimensional model to predict the unsteady behavior of turbocharger turbines for internal combustion engine applications. International Journal of Engine Research, 2018: 1468087417752525. 
[15] Padzillah, M.H., S. Rajoo, M. Yang, and R.F. Martinez-Botas, Influence of pulsating flow frequencies towards the flow angle distributions of an automotive turbocharger mixed-flow turbine. Energy Conversion and Management, 2015. 98: 449-462.

[16] Chen, H., I. Hakeem, and R.F. Martinez-Botas, Modelling of a Turbocharger Turbine Under Pulsating Inlet Conditions. Proceedings of the Institution of Mechanical Engineers, Part A: Journal of Power and Energy, 1996. 210: 397-408.

[17] Ding Z., Zhuge W., Zhang Y., Chen H., Martinez-Botas R, Yang M, A one-dimensional unsteady performance model for turbocharger turbines, Energy, 2017. 132: 341-355.

[18] Galindo, J., P. Fajardo, R. Navarro, and L.M. García-Cuevas, Characterization of a radial turbocharger turbine in pulsating flow by means of CFD and its application to engine modeling. Applied Energy, 2013. 103: 116-127.

[19] Padzillah M.H., Rajoo S., Yang M., Martinez-Botas R.F., Influence of pulsating flow frequencies towards the flow angle distributions of an automotive turbocharger mixed-flow turbine, Energy Conversion and Management, 2015. 98: 449-462.

[20] Hamel M., Abidat M. and Litim S. A., Investigation of the mixed flow turbine performance under inlet pulsating flow conditions, Comptes Rendus Mécanique, 2012. 340, 3: 165-176.

[21] Galindo, J., Serrano, J.R., Garcia-Cuevas, I.M. and Medina, N., Using a CFD analysis of flow capacity in a twin-entry turbine to develop a simplified physics-based model, 2021. 112: 106623.

[22] Vijayakumar R., Akehurst S., Liu Z., Reyes-Belmonte M.A., Brace C.J., Liu D., Copeland C., Design and testing a bespoke cylinder head pulsating flow generator for a turbocharger gas stand. Energy, 2019. 189: 116291.

[23] Roclawski, H., M. Gugau, F. Langecker, and M. Bohle. Influence of degree of reaction on turbine performance for pulsating flow conditions. in ASME Turbo Expo: Turbine Technical Conference and Exposition. 2014. Dusseldrof, Germany.

[24] Roclawski, H., M. Bohle, and M. Gugau. Multidisciplonary Design Optimisation of Mixed Flow Turbine Wheel. in ASME Turbo Expo, GT2012-68233. 2012. Copenhagen, Denmark.

[25] Hellström, F., U. Renberg, F. Westin, and L. Fuchs, Predictions of the Performance of a Radial Turbine with Different Modeling Approaches: Comparison of the Results from 1-D and 3-D CFD. SAE technical paper series, 2010.

[26] Tabatabaei, H.R., M. Boroomand, and M. Taeibi-Rahi, Pulsating Flow Analysis in a Small Turbocharger Turbine. International Journal of Science and Engineering Investigations, 2012. 1: 85-91.

[27] Lee, S.P., A. Rezk, M. Jupp, and K. Nickson, The influence of pulse shape on the performance of a mixed flow turbine for turbocharger applications. International Journal of Mechanical Engineering and Robotics Research, 2018. 7. 
[28] Galindo, J., S. Hoyas, P. Fajardo, and R. Navarro, Set-Up Analysis and Optimization of CFD Simulations for Radial Turbines. Engineering Applications of Computational Fluid Mechanics, 2013. 7: 441-460.

[29] Lee, S., S. Barrans, M. Jupp, and A. A Nickson, The Impact of Volute Aspect Ratio on the Performance of a Mixed Flow Turbine. Aerospace, 2017. 4: 2226-4310.

[30] Mahfoudh, C. and G. Adel, Analyses of steady and unsteady flows in a turbocharger's radial turbine. Proceedings of the Institution of Mechanical Engineers, Part E: Journal of Process Mechanical Engineering, 2015. 229: 130-145.

[31] Otoguro, Y., Takizawa, K., Tezduyar, T.E., Nagaoka, K., Mei, S., Turbocharger turbine and exhaust manifold flow computation with the space-time variational method and isogeometric analysis. Computers and Fluids, 2019. 179: 764-776

[32] Xin Q., Diesel Engine System Design. Woodhead, 2011.

[33] SAE, Surface Vehicle Recommended Practice, in Turbocharger Gas Stand Code. 2014, SAE Publications. 11.

[34] Borgwarner Turbo Systems, I., Turbocharger turbine map. 2013: 1849 Brevard Rd, Arden, NC 28704, USA.

[34] Burke, R.D., C.R.M. Vagg, D. Chalet, and P. Chesse, Heat transfer in turbocharger turbines under steady, pulsating and transient conditions. International Journal of Heat and Fluid Flow, 2015. 52: 185-197.

[36] Zimmermann, R., S. Hakansson, R. Baar, and L. Enghardt, Investigation on Pulsating Turbine Flow Radial Turbines, in 24th Aachen Colloquium Automobile and Engine Technology. 2015.

[37] Lee, S. P., Jupp, M. L., Barrans, S. M., \& Nickson, A. K., Analysis of leading edge flow characteristics in a mixed flow turbine under pulsating flows. Proceedings of the Institution of Mechanical Engineers, Part A: Journal of Power and Energy, 2019. 233(1), 78-95.

[38] Yang, M., R. Martinez-Botas, S. Rajoo, T. Yokoyama, and S. Ibaraki, An investigation of volute crosssectional shape on turbocharger turbine under pulsating conditions in internal combustion engine. Energy Conversion and Management, 2015. 105: 167-177.

[39] Padzillah M.H., S. Rajoo, and R.F. Martinez-Botas, Influence of speed and frequency towards the automotive turbocharger turbine performance under pulsating flow conditions. Energy Conversion and Management, 2014. 80: 416-428. 


\section{Table caption list}

Table 1 - The geometrical data of the simulated turbine 


\section{Figure caption list}

Figure 1 - The simulated geometry (a) Turbine grid: (a) volute grid, (b) rotor grid and (c) mid-span mesh and (d) computational domains.

Figure 2 - Efficiency and mass flow values for various grids normalised by the value computed for the finest grid.

Figure 3 - Engine pulses developed through a full engine cycle runs at $1500 \mathrm{rpm}$ using GT-Power engine model.

Figure 4 - Schematic of standard turbocharger gas stand [32].

Figure 5 - CFD Model Validation. N1, N2 and N3 are turbine speed. N1=133102 rpm, N2=161922 rpm, N3=185889 rpm

Figure 6 - Volute inlet pulsating mass flow, Pulsation Number $=1$.

Figure 7 - Volute mass flow accumulation determined using different inlet pulse shapes.

Figure 8 - Average Cycle efficiency of different pulse shapes and amplitudes

Figure 9 - The instantaneous efficiency in time domain

Figure 10 - the instantaneous $\mathrm{U} / \mathrm{C}_{\mathrm{s}}$ in the time domain

Figure 11 - Pulsating flow operating points - subgroups analysis 